\begin{abstract}
Resumo
O presente artigo faz uma revisão da apreciação de Bruno Taut feita por historiadores da arte e da arquitetura. Embora Taut venha sido considerado um utópico ou visionário, interpretamos seu trabalho como uma tentativa de lidar com as questões estéticas e políticas de seu tempo através de princípios distintos do racionalismo estrito. Descrevemos a concepção de arquitetura de Taut, com atenção especial ao uso da cor em seus projetos, como postura filosófica e crítica e engajada da realidade.
\end{abstract}

Palavras-chave: arquitetura moderna, Alemanha, Bruno Taut.

presente texto aborda a obra e as idéias do arquiteto e artista Bruno Taut. Destaca sua contribuição ao pensamento crítico que fundou a arquitetura culta dominante da primeira metade do século XX.

A amizade do arquiteto com seu amigo escritor Paul Scheerbart exemplifica a relação da arquitetura com as outras áreas do conhecimento. Essa inter-relação tornou-se um dos ingredientes importantes para a fluidez, abrangência e fundamentação crítica do movimento que revolucionou a cultura na virada do século.

Bruno Taut tinha grande interesse pela questão da cor na arquitetura. Sua militância em defesa da cor repercutiu no meio artístico e causou problemas para seu futuro profissional. A recuperação do pensamento de Taut é uma tentativa de buscar nos princípios do movimento moderno temas que podem oxigenar o debate da arquitetura contemporânea.

\section{Bruno Taut}

A passagem para o século XX foi turbilhonada por uma série de eventos ocorridos em diversas áreas

\section{Cláudio S. B. Furtado}

Arquiteto, professor da Faculdade de Arquitetura e Urbanismo da Universidade de São Paulo (FAU-USP), Alameda Lorena 319, ap. 53, Jardim Paulista, CEP 01424-001, (11) 9219-2772, cfurtado@usp.br que desestabilizou as teorias históricas e críticas da artes. Na tentativa de reunir os fragmentos de eventos num conjunto coerente, historiadores e críticos selecionaram fatos e personagens e negligenciaram os que não se adequavam a ele. O momento histórico atual requer a revisão de passagens obscurecidas a fim de preencher lacunas deixadas pela história e crítica da arte e da arquitetura.

Com o propósito de restabelecer conexões para a compreensão da modernidade, o historiador e crítico Reyner Barham escreveu em 1959 o artigo "O paraíso de vidro" (Revista Art in América, 11/97). Nele, o autor confessa sua negligência para com o significado de Bruno Taut na história da arquitetura e da arte moderna. A historiografia da arquitetura tem sido controversa quanto a Bruno Taut e os grupos "Novembergruppe" e "A Corrente de cristal". Por um lado Denis Sharp, em Arquitetura Moderna e Expressionismo cita a correspondência de "A Corrente de Cristal", lançada por Bruno Taut em novembro de 1919, como provavelmente a "mais importante troca teórica de idéias na arquitetura do século XX". Por outro lado, o teórico alemão Nicolau Pevsner ignora Taut tanto na História da 
Arquitetura Ocidental quanto em Os Pioneiros do Desenho Moderno. Gian Carlo Argan, Leonardo Benévolo e outros fazem referências modestas ao "Pavilhão de Vidro" projetado por Bruno Taut para a exposição da Werkbund em Colônia, em 1914.

Tal pavilhão tinha a forma de um tambor poligonal colocado sobre uma base de concreto com paredes de tijolos de vidro e uma cúpula de vidro facetado. A originalidade, o arrojo e a elegância do projeto o levaram a ser considerado como a manifestação de uma nova tendência expressionista na arquitetura alemã (LIPFER). Impressiona ainda a epígrafe do poeta Paul Scheerbart impressa na fachada do prédio: "o vidro colorido amortece o ÓDIO".

Em 1919 o expressionismo alemão equiparava-se em energia imaginativa e impacto com o movimento "Dada". Durante a República de Weimar houve um fervilhar da cultura germânica, que agregou uma geração de intelectuais de enorme influência na história cultural do século XX, tanto no campo da arquitetura, com nomes como Behrens, Loos, Mies Van der Rohe e Gropius e nas demais áreas como os de Franz Kafka, Sigmund Freud, Walter Benjamin, Georgy Luckács, Richard Straus, Gustav Mähler, Arnold Schönberg, Oskar Kokoschka, Gustav Klint e Bertold Brecht, entre outros. Em meio a tantos nomes importantes, o de Bruno Taut não teve visibilidade; ficou identificado com sua preocupação com a cor e projetos fantásticos e aparentemente inexeqüíveis. Se por uma lado Gropius teve a oportunidade de desenvolver seu talento na Bauhaus e posteriormente nos Estados Unidos, Taut teve de abdicar da direção da Bauhaus e posteriormente se exilou na Turquia.

As preocupações de Bruno Taut levaram-no a pensar a arquitetura conectada ao pensamento urbanístico, o que o envolveu no movimento das "cidades-jardins". Trabalhou na administração pública, em 1912, quando traçou os planos das cidades de Falkenberg, em Belin-Grünau, e da cidade-jardim Reform, em Magdeburg. O início da Primeira Guerra obriga-o a cessar suas atividades profissionais e a procurar alternativas produtivas neste período de destruição:

Eu quero fazer uma proposta para vocês. Hoje não há quase nada a construir, e se conseguirmos construir algo em algum lugar, o faremos para sobreviver. Ou você tem sorte suficiente para trabalhar numa boa comissão? Minha rotina diária me deixa doente, é basicamente o mesmo para todos vocês. Mas, por incrivel que pareça, é uma coisa boa que nada esteja sendo construído hoje. As coisas terão tempo para amadurecer, nós devemos tomar nosso rumo e, quando as construções começarem, nós saberemos quais são nossos objetivos e estaremos fortes $o$ suficiente para proteger nosso movimento contra emendas e degenerações (WHYTE, 1985, p. 19).

Com estas palavras, em 24 de novembro de 1919 forma-se o "Novembergruppe" e Taut lidera uma confraria semi-secreta de artistas, arquitetos, poetas e pensadores denominada "Cadeia-de-cristal". Os escritos teóricos e desenhos deste período são freqüentemente classificados como utópicovisionários, mas Reyner Barham, Jürgen Paul e Paul Sigel, assim como o próprio Taut, não os viram assim. Seus projetos constituíram-se não numa ergoterapia ou em exercícios utópicos, mas numa consistente e densa reflexão sobre o papel da arquitetura na sociedade moderna, que, mesmo recheada de esoterismos, converteu-se numa radical critica à sociedade industrial.

O critico Özer Bülent divide a carreira do arquiteto em três fases. A primeira, "caracterizada por progressiva experimentação em materiais e técnicas modernos", foi até 1918, período em que ele erigiu o Monumento de aço e sua mais famosa construção, o Pavilhão de vidro. O segundo período compreende a época da guerra e das revoluções na Alemanha: "Taut, o visionário com aspirações utópicas, fazendo acrobacias no ar sem tocar no chão". É nessa fase que ele projeta sua "Arquitetura Alpina". O terceiro período é marcado por um severo realismo, em que sua obra ultrapassa os limites do "International Style", na linguagem de Bülent, mostrando fascinação por um tipo de romantismo expressionista; este período se caracteriza pelo envolvimento de Taut com a construção de casas. Com a ascensão do nazismo, em 1933, ele deixa a Alemanha e, depois de uma rápida passagem pelo Japão, se estabelece em Istambul, onde morre aos 58 anos na casa multicolorida que projetou.

Assim como Le Corbusier, Taut não abandona sua atividade inicial de desenhista com carvão e pastel e seu interesse pela gravura japonesa o leva a se refugiar no Japão posteriormente. Em seu diário, 
na data de 17 de março de 1905, expõe as idéias que o ocupavam nos últimos anos: unir o talento no uso da cor à habilidade arquitetônica. Em 23 de dezembro daquele ano, escreve: "O pintor em mim está subordinado ao arquiteto - e isso está na minha natureza. Para mim a pintura nunca poderá ser um fim em si mesmo" (WHYTE, op.cit.). Em 1912, Bruno Taut desenhou um conjunto habitacional em Falkenberg, no estado de Berlin-Grünau. Eram 128 unidades habitacionais, entre residências e apartamentos, alinhados ao longo de um extenso terraço. Este conjunto ficou conhecido como "caixa de pintura", pois Taut usou toda a escala de cores, na tentativa de trazer a natureza à cidade, criando "harmonia na diversidade". As cores eram o verde, o castanho, o azul e o rosa, os mesmos tons das pinturas naturalistas que antes realizou no local. Numa viagem à Lituânia Taut soube que no dialeto de origem de sua família seu nome significava "folclore - folk", e isso contribuiu para sua crença quase "revelada": as obras vernaculares da arquitetura são prioritariamente coloridas; cinza, branco e preto vinham da arquitetura Art Nouveau dos prédios da burguesia. Esta foi a inspiração para o manifesto "Em busca de uma arquitetura colorida", de 1919, co-assinado por Bruno e Max Taut, Walter Gropius, Peter Behrens, Hans Scharoun, Adolf Behne, entre outros. Gropius foi além ao propor o uso da cor como protesto contra a austera, cinzenta situação econômica vivida na época pela Alemanha e tomou como modelo o uso exuberante da cor na arquitetura russa camponesa.

Entre 1921 e 23, Taut foi diretor de construções do município de Magdeburg, onde praticou em larga escala seus planos urbanos e pôs em prática seu manifesto de 1919. As fachadas da cidade, naqueles anos cinzentos e depressivos, foram pintadas com cores fortes. O arquiteto dizia que sua atividade era mais ética que estética, uma vez que pretendia propiciar aos habitantes dos mais sórdidos e insalubres quintais um raio de joie de vivre, por meio da pintura com cores alegres. No dizer de Taut, "arquitetura é música gelada, mas em Magdeburg ela foi descongelada"(STUARTT, 1999)

À experiência urbana de Magdeburg seguiu-se um conjunto de 10.000 apartamentos em Berlim. O conjunto Hufeisensiedlung Britz (conjunto de ferradura em Blitz) apresenta uma grande variedade de cores, que contrastam com os pinheiros da paisagem e o azul do céu, formando um colorido de contrastes entre o prédio e o entorno. Em outro conjunto a palheta de cores se altera em função da paisagem, que não é mais composta de pinheiros. Assim, Taut não obedece a um esquema cromático rígido, mas adapta-se a cada situação do entorno. Suas pesquisas com a cor não se limitaram à função ética. Em seus projetos berlinenses, e depois nos de Intanbul, ele investigou a influência da cor na percepção do espaço, no conforto e na economia de energia. "A forma da casa corresponde à cristalização das condições atmosféricas patrocinadas pela cor" (WHYTE, 85, p. 19). Surpreendentemente, Taut usa o preto e o branco, respectivamente para aumento e diminuição da temperatura em paredes pouco ensolaradas, e com isso cria tensões e movimentos. Sobre as cores dos apartamentos de Berlim, Winfried Brenne comenta:

Taut sempre usava a cor para fazer com que a arquitetura atingisse uma dimensão extra. Ele sabia que a cor desenvolve um efeito plástico e confere um caráter específico ao espaço urbano, contribuindo com a paisagem do entorno. Ele lutou para que o uso da cor fosse além da noção funcional da arquitetura, com o objetivo de criar uma forma de produzir prédios harmoniosos englobando as dimensões humanas e artísticas (BRENNE In WHYTE, 85, p. 19).

\section{As cartas da Corrente de Cristal}

A Primeira Guerra e a revolução alemã em novembro de 1918 levaram Taut a se mover. Pouco depois fundou a AFK (Arbeitsrat für Kunst), Conselho de trabalho para Arte. Suas intenções, entretanto, não foram bem entendidas pelo governo, que confundiu seu empenho artístico com propósitos políticos. Assim, a chefia do conselho foi substituída e atribuída a Walter Gropius que, apesar de concordar completamente com as idéias do antecessor, mantinha-se firmemente afastado de qualquer comprometimento político. No manifesto da fundação da AFK, Taut afirmou que a arquitetura é a líder natural das artes plásticas e concluiu que as contribuições das demais artes levariam a que se atingisse uma nova arquitetura. Convocou então os membros da associação para uma "exposição de arquitetos anônimos" que aconteceu em Berlim em abril de 1919 e provocou furor da crítica e o estreitamento dos laços entre os expositores. 
Entre eles estavam os irmãos Bruno e Max Taut, Gropius e Rudolf Salvisberg. Tal estreitamento sugeriu a Bruno a idéia de expressar conscientemente suas idéias visionárias como caminho para uma revolução artística abandonando os princípios da lógica estabelecida e propondo "semear em húmus fresco"

Os membros do "Novembergruppe" tinham cada qual um codinome e assemelhavam-se a uma confraria esotérica. No entanto, às regras secretas da sociedade se impôs a vaidade do líder e, um mês depois, na própria revista que convocou a exposição, Taut traiu o pacto de sigilo, ao publicar o manifesto que provocou irremediáveis cisões no grupo.

O que não ficou claro para os historiadores da arquitetura foi o caráter visionário do "Novembergruppe". Seus projetos eram imaginativos como as obras mais radicais do dadaísmo, mas se fincavam também em solo firme. Classifica-los como utópicos reflete a visão dos que viram as histórias das utopias correrem paralelas, quase congruentes, com a história do pensamento urbanístico. A associação entre as formas de organização social e de organização espacial até então tinham feito parte da historiografia, entretanto há em Bruno Taut e seu grupo uma dissociação entre imaginação e utopia. Eles não pensam uma nova sociedade e vão à procura de uma geometrização condizente com a sua organização. Não se trata de construir um novo espaço para uma nova função, mas de criar novas formas que dêem a esta sociedade, assim como está, melhores condições não só funcionais, mas como nova alegoria vivencial. A arquitetura é pensada por Taut como mais uma das formas artísticas nas quais o homem pode se ver e sonhar e não apenas uma forma concreta de um sonho, nem sempre claramente explicitado. Ele vê na liberdade imaginativa as possibilidades de levar usuários e espectadores a partilhar tais capacidades e que cabe ao arquiteto apenas lhes abrir espaços alegóricos.

A cidade projetada toda de vidro, que desce dos Alpes até o mar, é uma arquitetura fantástica, mas não utópica. O lugar é determinado, a tecnologia do aço e vidro já havia sido testada no pavilhão da feira de Colônia. Talvez os recursos financeiros para sua execução não ultrapassassem os custos dos armamentos armazenados para a guerra que se prenunciava. A única dificuldade de execução de tal obra estava em convencer as autoridades das prioridades espirituais, culturais e mesmo místicas frente às premências das guerras mundiais. Tal imaginação, isenta de um pensamento revolucionário, se desvencilha das leituras racionalistas cuja lógica, em sua visão, levou a humanidade à modernidade tecnológica e conseqüentemente às barbáries das grandes guerras. Ao se colocar nesta posição, Bruno Taut afasta-se das ideologias revolucionárias tanto quanto das forças organizadas que se preparavam para tomar o poder na Alemanha.

A influência do poeta Paul Scheerbart e principalmente as idéias do filósofo Nietzsche são visíveis nas correspondências da "corrente de cristal". Provavelmente Taut entrou em contato com o texto de Nietzsche "Die fröhliche Wissenschaft", onde se lê:

Arquitetura para a busca do conhecimento - Um dia, e provavelmente logo, nós precisaremos reconhecer o que acima de tudo falta às nossas grandes cidades: vastos e silenciosos espaços para reflexão... Foi-se o tempo em que a igreja possuía o monopólio da reflexão, em que a vita contemplativa tinha que ser antes de mais nada vita religiosa, e em que tudo construido ao redor das igrejas expressava essa idéia. Eu não vejo como poderemos ficar satisfeitos com prédios dessa espécie, ainda que fossem despidos de seus propósitos clericais. A linguagem falada por esses prédios é plena de retórica e submissão, lembrando-nos que são casas de Deus e monumentos ostentatórios das relações supra-mundanas; nós, que somos ateus, não podemos desenvolver nossos pensamentos nesse tipo de ambiente. Nós queremos ver-nos traduzidos em pedras e plantas; queremos caminhar em nós mesmos enquanto passeamos em volta de tais prédios e jardins (Friedrich Nietzsche, Die Fröehliche Wissenschaft, apud WHYTE, 1985, p. 4).

No projeto "A coroa da Cidade", Taut concebe uma cidade ideal em cujo centro se ergue um enorme prédio envidraçado sem qualquer utilização determinada - a Casa de Cristal. Segundo uma hierarquia de importância que vai do centro para a periferia, o centro de vidro pleno de luz é o ponto culminante de sua concepção urbanística (BARHAM, p. 258). 
Benévolo dedica uma pequena nota sobre o grupo de Taut, sem mesmo citá-lo, numa passagem sobre a formação do movimento moderno (1918-27), incluindo-o entre as correntes vanguardistas formadas na época da guerra, empenhadas em experiências que contestavam a lógica racional dos modernos. Reyner Barham dedica-lhe três páginas em seu livro Teoria e desenho arquitetônico na era da máquina (ibidem p. 257-259). A importância ali atribuída a Taut está na sistematização da experiência expressionista em seu manifesto "A coroa da cidade", "por tratar-se de um dos poucos documentos importantes da fase expressionista..." (idem ibidem) O tratado escrito por Paul Scheerbart dedicado a Taut foi rapidamente tachado como documento de literatura fantástica. Finalmente Argan Ihe dedica um longo parágrafo em Arte Moderna:

A arquitetura expressionista se desenvolveu no clima agitado do pós-guerra alemão. Era preciso reconstruir uma sociedade em ruínas: as forças democráticas queriam uma economia de paz e cooperação internacional; as forças reacionárias queriam uma economia que prepara um novo esforço bélico, a revanche. Os arquitetos percebem que representam o espírito "construtivo" da nova Alemanha democrática, tomam consciência da importância de sua condição de técnicos responsáveis. Agrupam-se, organizam-se, inserem-se no processo revolucionário que vinha se desenvolvendo no país (e que será decapitado pelo nazismo), isto é, seguem o exemplo da "vanguarda" artística russa, que vinculara o processo de renovação da arte ao processo revolucionário da sociedade. Institui-se um Conselho do trabalho para a Arte, forma-se o Grupo de novembro (Novembergruppe), núcleo de pesquisa e experimentação da construção civil e, ao mesmo tempo, elemento de pressão para conseguir que o Estado apóie as novas experiências, voltadas para um urbanismo capaz de responder às exigências de vida e de trabalho do povo, e não subordinado ao lucro dos especuladores. A alma do grupo é BRUNO TAUT (1880-1935); participam do movimento praticamente todos os arquitetos "modernos", desde os mais velhos, como Poelzig e Behrens, aos mais jovens, como E. MENDELSOHN (1887- 1953) e H. SCHAROUN (1893-1972). A orientação do Grupo de Novembro pode parecer utópica, arbitrária, aberrante - a Alemanha do pós-guerra necessitava de algo muito diferente das fantasias arquitetônicas, como as de Finsterlin, de improváveis "cidades alpinas", de imaginários "teatros de massa" onde finalmente se realizaria o sonho, mais wagneriano do que expressionista, da "obra de arte total", síntese unânime de todas as artes. Na verdade, o Grupo de Novembro teve vida breve: seus homens de ponta, como Gropius e o próprio Taut, logo se colocam à frente do rigoroso racionalismo arquitetônico alemão. É importante, porém, que, nos anos imediatamente posteriores à guerra, tenha-se recorrido à invenção e à criação como antídoto à depressão geral, tenha-se aberto o campo à experimentação formal mais audaz, tenhase procurado utilizar todas as novas sugestões que haviam se manifestado no âmbito do modernismo arquitetônico, incluindo Gaudi (ARGAN, 1993, p. 246).

Ainda que o projeto da "Coroa da cidade" tenha algo de cidade-jardim e algo da utopia de Charles Fournier (1772-1837), não chega a ser propriamente uma utopia. Organizado a partir de uma estrutura biaxial em que o poder público ocupa o retângulo central, a cidade é ladeada por uma imensa torre de vidro sem qualquer utilidade, como uma catedral gótica que centraliza o espaço de pensamento e da introjeção, referido no texto de Nietzsche. Seu projeto não é utópico. Não projeta uma nova sociedade em lugar algum, mas nos Alpes, e apresenta sua construção como efetivamente possível, se não no presente de guerra, ao menos no imediato pósguerra. A idéia de Taut de um grande palácio de luz no centro da cidade se vincula a um texto de Paul Scheerbart, que também influenciou enormemente um outro filósofo.

Dentre os mais de trezentos textos de Scheerbart, os que mais impressionaram Walter Benjamin e Taut foram A roupa cinza e dez por cento de branco: uma novela para uma dama (Das graue Tuch und zehn Prozent Weiss: Ein Damenroman), de 1914, e Lesabéndio: uma novela asteróide (Lesabéndio: Ein Asteroïden Roman), de 1913. A história de Lesabéndio conta a vida em Pallas, um asteróide localizado no cinturão de Kuiper e habitado pelos Pallasianos. Sem governo ou instituições, os Pallasianos se unem para saber o que brilhava sobre as nuvens que os cobriam. Lesabéndio, um astrônomo, convence a população a construir um imenso observatório que subisse acima das nuvens. Com sete milhas de altura a torre construída possibilitou aos Pallasianos dramáticas transformações, graças ao conhecimento 
do céu e a reconfiguração de suas vidas paradisíacas, naturalistas, no asteróide que habitavam. Walter Benjamin descreve este romance como um dos que mais o influenciaram (SCHOLEM e ADORNO, 1994, p. 153-155).

Quando Benjamin diz que "a imagem é a dialética em repouso", que não encontra seu lugar em nenhuma realidade, talvez explique os projetos de Taut e Scheerbart nos Alpes. Eles não estão projetando cidades, estão tratando arquitetura como arte. Já que a realidade não lhes oferece um local para erguer cidades, erguem imagens. A passagem sobre as nuvens significa o contato não pelo intelecto, mas pela embriaguez, a contestação do progresso técnico a serviço da guerra e da catástrofe. Um texto de Benjamin que parece se referir a esta influência é o último parágrafo de Rua de Mão Única, "A caminho do planetário":

'A Terra pertencerá unicamente àqueles que vivem das forças do cosmos'. Nada distingue tanto o homem antigo do moderno quanto sua entrega a uma experiência cósmica que este último mal conhece. O naufrágio dela anuncia-se já no florescimento da astronomia, no começo da Idade Moderna. Kepler, Copérnico, Tycho Brahe certamente não eram movidos unicamente por impulsos científicos. Mas, no entanto, há no acentuar exclusivo de uma vinculação ótica com o universo, ao qual a astronomia muito em breve conduziu, um signo precursor daquilo que tinha de vir. O trato antigo com o cosmos cumpria-se de outro modo: na embriaguez. É embriaguez, decerto, a experiência na qual nos asseguramos unicamente do mais próximo e do mais distante, e nunca de um sem o outro. Isso quer dizer, porém, que somente na comunidade o homem pode comunicar em embriaguez com o cosmos. Éo ameaçador descaminho dos modernos considerar essa experiência como irrelevante, como descartável, e deixá-la por conta do indivíduo como devaneio místico em belas noites estreladas (BENJAMIN, Rua de mão única, 1994,V 2, p. 68).

Num texto de Olgária Matos sobre Descartes e Benjamin o sentido de Lesabéndio se esclarece:

O trato antigo com o cosmos cumpria-se de outro modo: na embriaguez. Éo ameaçador descaminho dos modernos considerar experiência como irrelevante (...) e deixá-la por conta do indivíduo como devaneio em belas noites estreladas. Não, ela chega sempre e sempre de novo a seu termo de vencimento, como se patenteou na maneira mais terrível na última guerra (Primeira Guerra), que foi um ensaio de novos, inauditos esponsais com as potências cósmicas. Massas humanas, gases, forças elétricas foram lançadas ao campo aberto, correntes de alta tensão atravessaram a paisagem, novos astros ergueram-se no ar, espaço aéreo e profundezas marítimas ferveram de propulsores, por toda parte cavaram-se poços sacrificiais na Mãe Terra. Essa grande corte feita ao cosmo cumpriu-se pela primeira vez em escala planetária, ou seja, no espírito da técnica (MATOS, 1993, p. 59/60).

Nas propostas de Taut, do Grupo de novembro, do escritor Scheerbart e do pensador Benjamin pode ser encontrada a antítese da visão mecanicista, linear, que coloca o homem como senhor do universo, capaz e capacitado para moldar a natureza à sua vontade. São propostas de imaginação utópica e também são ficções que abrem caminhos para o devaneio. Trata-se da postura crítica que incorpora a embriaguez ao arcabouço dos conhecimentos necessários ao homem para sua libertação.

Scheerbart semeou seu último romance com motivos arquitetônicos. Stuart, tradutor para o inglês, coloca-o entre as mais importantes realizações literárias de inspiração em relevantes temas arquitetônicos ao lado de Petite Maison de Jean-François Bastide, News from Nowhere, de William Morris, Major Bárbara, de George Bernard Shaw, The Fountainhead, de Ayn Rand e O nome da rosa de Umberto Eco. A roupa cinza e dez por cento de branco conta a história de Edgar Krug, um arqueólogo suíço que se torna arquiteto e que num navio-voador põe-se a percorrer o mundo, realizando projetos fantásticos. Em meados do século XX, Krug constrói prédios em vidro colorido: um aranhacéu em Chicago, que abriga um centro de exposições e uma sala de concerto; um centro de descanso para pilotos de navios fantasmas numa torre nas Ilhas Fiji; a estrutura de um trem aéreo sobre um zoológico no norte da Índia e uma cidade suspensa nas ilhas Cúria Maria, nas costas de Omã, na Península Arábica. Em Chicago, Krug conhece Clara, uma pianista, e lhe propõe casamento. Para que as cores de suas roupas não interfiram na concepção das cores da arquitetura, elabora um extenso contrato pelo qual a esposa ficará obrigada a se vestir somente com roupas cinza, com dez por 
cento de branco. Depois de várias ocorrências pelo mundo, as regras do matrimônio são finalmente abrandadas e algumas das razões ficam explícitas; outras, porém, permanecem inexplicáveis.

Taut conheceu Scheerbart poucos anos antes de sua morte, primeiro através de sua literatura. Em sua curta vida, contudo, Scheerbart foi um autor prolífero em sua curta vida produzindo ensaios, poemas e romances. Taut convidou o escritor para criar algumas epígrafes para a casa de vidro que pretendia expor em Colônia. Alguns autores invertem a relação, dizendo que foi Scheerbart que convenceu Taut a efetuar tal projeto. De qualquer forma, o prédio foi dedicado ao poeta; em contrapartida, Scheerbart dedicou-lhe um tratado de arquitetura com 111 verbetes.

As frases inscritas no pavilhão de vidro de Colônia, traduzidas para o inglês são: Glass in tints; Hate relents; A colorful future; Only in the glass culture; Wax ecstatic!; Glass is prismatic!; Flight from colour?; All the duller!

Há aqui uma estreita relação entre imagens poéticas e matéria construtiva. O vidro, tecnologia de ponta entre os materiais arquitetônicos, signo da modernidade e progresso, ao se colorir transformase em elemento contestatória aos tempos sombrios e frígidos. As características técnicas, utilitárias e funcionais do material são apropriadas pelos autores do projeto, sendo que a nova visibilidade que a cor dá ao material o transforma em matéria prima para o pensamento de vanguarda.

O caminho que a história da arquitetura percorreu ao adotar o racionalismo da Bauhaus, de Le Corbusier e os princípios da arquitetura acromática de Mies van der Rohe deixou para o campo do "devaneio místico em belas noites estreladas" as idéias coloridas de Bruno Taut, que procurou através do vidro duplo colorido um contraponto à estrutura ascética e impessoal dominante das cidades modernas. Paul Scheerbart pagou o preço do esquecimento pelo chamado para as luzes além das nuvens. No entanto, apesar das dificuldades de publicação e das negligências em relação ao poeta-arquiteto, Bruno Taut nos lembra que a luz, a cor e a embriaguez não podem deixar o terreno da arquitetura sem que percamos os caminhos de um universo radioso.

\section{Referências bibliográficas}

ARGAN, Giulio Carlo. Projeto e destino. Trad. Marcos Bagno. São Paulo, Atica, 2001.

Arte moderna. Trad. Denise Bottmann e Federico Carotti. São Paulo, Cia das Letras, 1993.

BANHAM, Reyner. Teoria y diseño arquitectónico en la era de la máquina. Trad. Luís Fabricant. Buenos Aires, Nueva Visión, 1965.

BENEVOLO, Leonardo. Historia de la Arquitectura Moderna. Trad. Mariuccia Galfetti e Juan Diaz de Atauri. Barcelona, Gustavo Gili , 1974.

BENJAMIN, Walter. Obras escolhidas, Livros II e III. Trad. José Carlos Martins Barbosa, Hemerson Alves Baptista e Rubens Rodrigues Torres Filho. São Paulo, Brasiliense, 1994.

LUPFER, G. E., PAUL, J. e SIGEL, P. Teoria da arquitectura: do renascimento até aos nossos dias. Trad. Maria do Rosário Paiva Boléo. Londres/Madri, Taschen, 2003.

MATOS, Olgária. "O céu da história e a tristeza do Brasil", in A outra margem do Ocidente. Adauto Novais (org.). São Paulo, Cia. das Letras, 1999.

O iluminismo visionário: Benjamin, leitor de Descartes e Kant. São Paulo, Brasiliense, 1999.

PEVSNER, Nikolaus. Panorama da Arquitetura Ocidental. Trad. Do inglês José Teixeira Coelho Neto. São Paulo, Martins Fontes, 2002.

SCHEERBART, Paul. The gray cloth. Londres, MIT Press, 2001, 1990.

WHITE, I. B. The Crystal Chain letters: architectural fantasies by Bruno Taut and his circle. Londres, MIT Press, 1985.

\section{Artigos}

MATOS, Olgaria. "Iluminação mística, iluminação profana: Walter Benjamin", in Revista discurso, no. 23, São Paulo, FFLCL USP, 1994.

STUART, J. A. "Unweaving narrative fabric: Bruno Taut, Walter Benjamin and Paul Scheerbart's The Gray Cloth", in Journal of Architectural Education. Association of Collegiate Schools of Architecture, Washington, p. 61-73, novembro de 1999. 